\title{
Detection of human epidermal growth factor receptor 2 protein and gene in fine needle aspiration cytology specimens and tissue sections from invasive breast cancer: Can cytology specimens take the place of tissue sections?
}

\author{
KAZUHIRO SUMIYOSHI $^{1,2}$, YURO SHIBAYAMA ${ }^{1}$, SHIZUKA AKASHI $^{1}$, TAKEHIRO NOHARA ${ }^{2}$, \\ MITSUHIKO IWAMOTO ${ }^{2}$, TOSHIHIRO KOBAYASHI ${ }^{2}$, HARUTO NISHIMURA ${ }^{2}$, \\ RYOJI YOSHINAKA ${ }^{2}$, TOMOAKI HARADA ${ }^{2}$ and NOBUHIKO TANIGAWA ${ }^{2}$
}

Departments of ${ }^{1}$ Pathology and ${ }^{2}$ General and Gastroenterological Surgery, Osaka Medical College, Osaka, Japan

Received October 11, 2005; Accepted December 19, 2005

\begin{abstract}
Overexpression of HER2 protein and HER2 gene amplification in breast cancer are prognostic factors for the response to specific medical treatments such as trastuzumab, endocrine therapy, and chemotherapy. Whereas HER2 expression and gene amplification are generally examined in tissue sections, we investigated whether specimens from fine needle aspiration cytology (FNAC) are adequate for these analyses. HER 2 protein overexpression and HER2 gene amplification were assessed in both FNAC specimens and tissue sections from 58 cases of invasive breast cancer. Immunohistochemistry assay for HER 2 protein expression was performed according to the HercepTest protocol, and HER2 gene amplification was examined with the Spot-light CISH (chromogenic in situ hybridization) Detection kit. There was a significant positive correlation between assessments of HER2 protein status in the cytology specimens and tissue sections. The sensitivity, specificity, and accuracy of HER2 gene amplification detection in cytology specimens in relation to those in tissue sections were $84.0 \%$ (21/25 cases), $87.9 \%$ (29/33 cases), and $86.2 \%$ (50/58 cases), respectively. FNAC specimens are suitable for detection of HER2 overexpression and HER2 gene amplification in invasive breast cancer.
\end{abstract}

\section{Introduction}

Overexpression of HER2 protein and HER2 gene amplification in breast cancer are prognostic factors for the response to

Correspondence to: Dr Nobuhiko Tanigawa, Department of General and Gastroenterological Surgery, Osaka Medical College, 2-7 Daigaku-machi, Takatuki City, Osaka 569-8686, Japan

E-mail: sur001@poh.osaka-med.ac.jp

Key words: invasive breast cancer, HER2, gene amplification, chromogenic in situ hybridization, fine needle aspiration cytology specimen, tissue section specific medical treatments such as trastuzumab, endocrine therapy, and chemotherapy (1-7). HER2 gene amplification or HER2 protein overexpression has been identified in 20$30 \%$ of human breast cancers $(8,9)$. HER 2 expression and gene amplification are generally examined in tissue sections; however, it would be beneficial if cytology specimens could be used because the method used to obtain such specimens is minimally invasive. Even in tissue samples obtained by core needle biopsy, it is often too difficult to assess HER2 status because the samples are very small or the cancer cells are crushed. Although some studies of HER2 status in cytology specimens have been reported (10-14), assessment of HER2 status in the cytology specimen has not been clearly defined. Moreover, no studies comparing cytology specimens and tissue sections with respect to HER2 expression and HER2 amplification have been reported. Therefore, the goal of the present study was to determine whether fine needle aspiration cytology (FNAC) specimens can be used for the assessment of HER2 gene amplification and HER2 overexpression.

\section{Materials and methods}

Patients. The study population consisted of 58 patients who underwent surgery for primary invasive breast cancer at Osaka Medical College (Japan). Patient and tumor characteristics are shown in Table I. The patients comprised 1 man and 57 women who ranged in age from 32-84 years. The tumors included 20 papillotubular carcinomas, 6 solid tubular carcinomas, 31 scirrhous carcinomas, and 1 mucinous carcinoma. During surgery, we used a fine needle to obtain an aspirate from the central part of the resected tumor, and prepared cytology specimens fixed in $95 \%$ ethanol. We later prepared sections from formalin-fixed, paraffin-embedded tissue specimens from the same cases. We compared HER2 status in cytology specimens and tissue sections. Histologic type was determined from sections of the central part of the tissue specimens.

Immunohistochemistry (IHC). IHC was done with the HercepTest (DakoCytomation). Tissue sections and cytology 

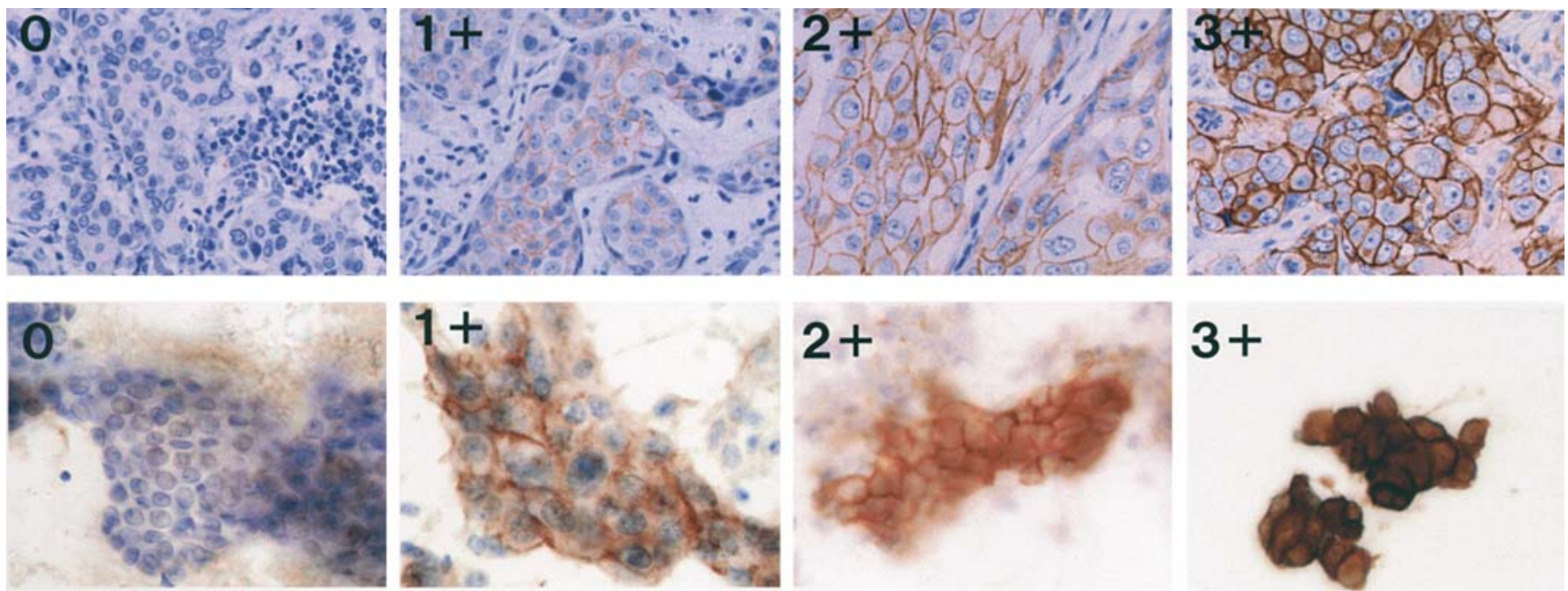

Figure 1. Criteria for scoring HER2 protein expression in tissue sections and FNAC specimens. Upper, tissue sections; lower, FNAC specimens. Samples were scored according to the HercepTest guidelines. Scores were: 0 , no staining or staining of $<10 \%$ of cancer cells; $1+$, slight staining; $2+$, intermediate staining; and $3+$, strong staining of $>10 \%$ of cancer cells
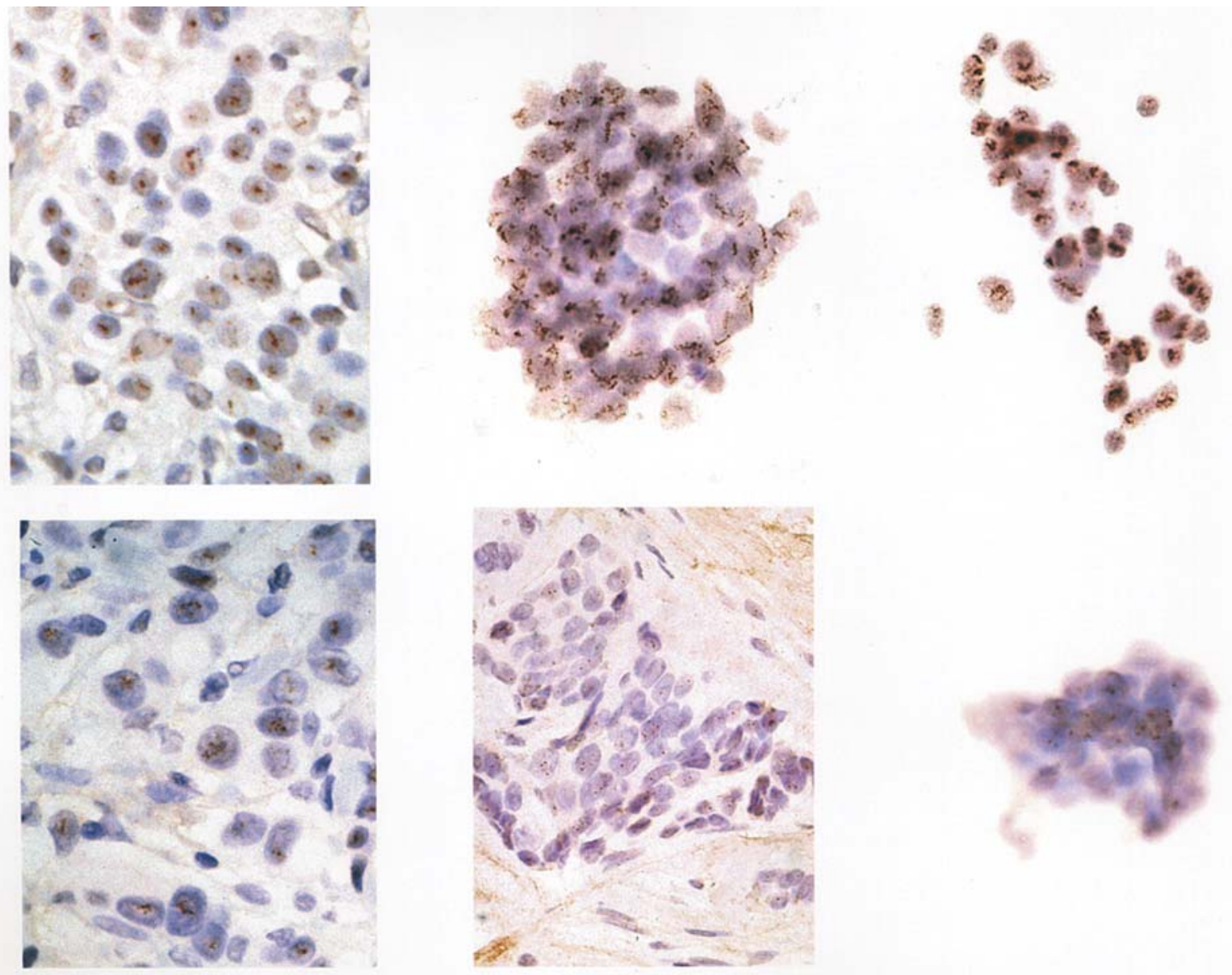

Figure 2. Criteria of HER2 gene amplification (CISH). Upper left, typical HER2/neu amplification appearing as clusters (score A); tissue section. Upper middle, typical HER2/neu amplification appearing as multiple dots (score B); FNAC specimen. Upper right, typical HER2/neu amplification appearing as clusters and multiple dots (score C); FNAC specimen. Lower left, typical HER2/neu amplification appearing as 5 to 10 dots (score D); tissue section. Lower middle, no amplification. A tumor with 1 or 2 clearly identifiable copies of the HER2/neu gene; tissue section. Lower right, no amplification; FNAC specimen. Original magnification, $\mathrm{x} 400$.

specimens were reacted with the anti-HER2 polyclonal antibody provided with the HercepTest (A485), then visualized using the Envision method (DakoCytomation). Tissue sections were deparaffinized before antigen retrieval in citrate buffer $(\mathrm{pH} 6.0)$ at $95^{\circ} \mathrm{C}$ for $40 \mathrm{~min}$, then $20 \mathrm{~min}$ at room temperature. Antigen retrieval was not performed for the cytology specimens. 

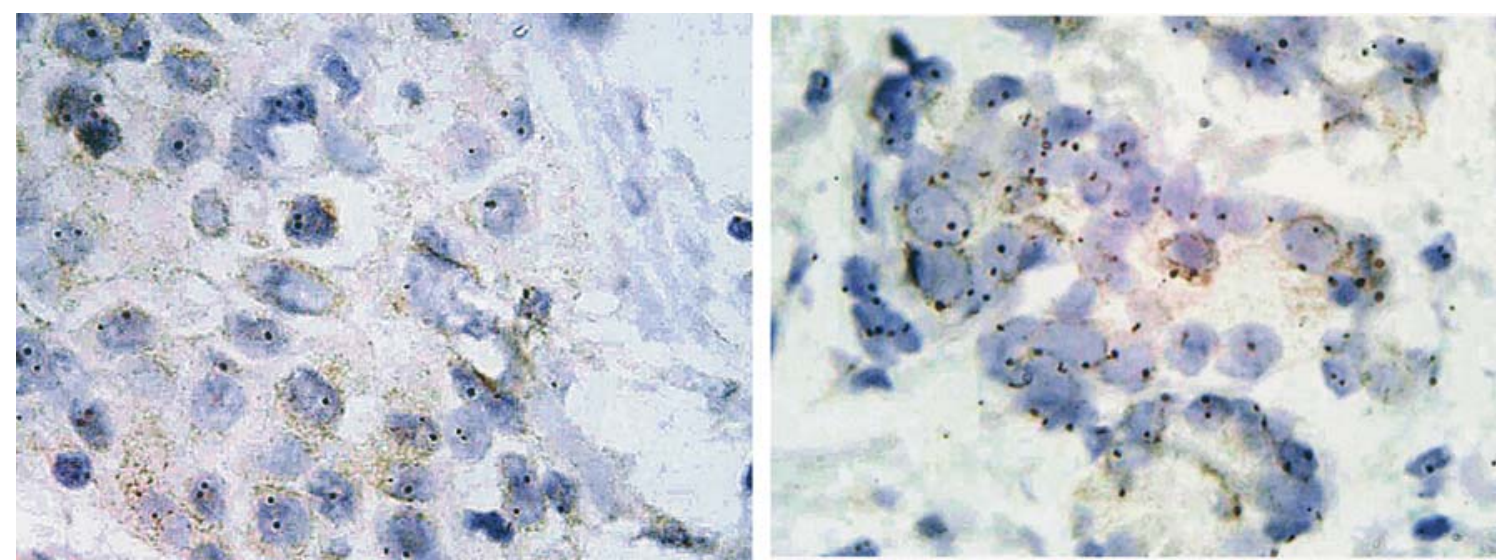

Figure 3. Chromosome 17 centromeric status. (Left) Two dots per cell: normal Chr 17; extra HER2 dots are caused by HER2 amplification. (Right) Three to 5 dots per cell: polysomy of Chr 17; extra HER2 dots are not caused by HER2 amplification.

Table I. Clinical characteristics of patients with invasive breast cancer.

\begin{tabular}{lc}
\hline Sex (M/F ratio) & $1: 57$ \\
Age (years) & $32-84$ (mean, 56) \\
Tumor size (mm) & $12-140$ (mean, 30) \\
Lymph node metastasis & \\
$\quad(-)$ & 27 \\
$\quad(+)$ & 31 \\
Invasive ductal carcinoma & \\
Papillotubular & 20 \\
Solid tubular & 6 \\
Scirrhous & 31 \\
Mucinous & 1 \\
\hline
\end{tabular}

Assessment of HER2 protein expression. HER2 protein levels were determined as described in the HercepTest manual (Fig. 1). Scores were: 0, no staining or staining of $<10 \%$ of cancer cells; $1+$, slight staining; $2+$, intermediate staining; and $3+$, strong staining; of $>10 \%$ of cancer cells. Correlation between data from cytology specimens and tissue sections was evaluated with Spearman's rank correlation coefficient.
Chromogenic in situ hybridization (CISH). CISH of tissue sections was done according to the protocol of the Spot-light CISH Detection kit (Zymed Inc.). Sections were deparaffinized, and incubated in a $95^{\circ} \mathrm{C}$ water bath for $15 \mathrm{~min}$. Sections were then treated with proteinase $\mathrm{K}$ at room temperature for $10 \mathrm{~min}$. Endogenous peroxidase activity was blocked with $3 \% \mathrm{H}_{2} \mathrm{O}_{2}$ in methanol, and samples were then air dried. Digoxigenin-labeled HER2 probe $(15 \mu 1)$ was applied to the sections, which were then covered with coverslips. Slides were denatured on a hot plate at $80^{\circ} \mathrm{C}$ for $3 \mathrm{~min}$, and hybridization was performed overnight (16-24 h) at $37^{\circ} \mathrm{C}$. To remove the coverslips, the slides were soaked in $1 \mathrm{X}$ Tris-buffered saline containing $0.1 \%$ Tween-20. Slides were then washed with a stringent wash solution at $75^{\circ} \mathrm{C}$ for 5 min. Samples were blocked with normal serum, then incubated with mouse anti-digoxigenin and polymerized HRP-anti-mouse antibody for $60 \mathrm{~min}$ at room temperature. Binding was visualized with 3,3'-diamino benzidine.

For cytology specimens, a slightly modified protocol was used. Briefly, after enzymatic digestion, cells were re-fixed with $4 \%$ paraformaldehyde at room temperature for $15 \mathrm{~min}$. Slides were denatured on a hot plate at $90^{\circ} \mathrm{C}$ for $3 \mathrm{~min}$ and hybridized overnight at $37^{\circ} \mathrm{C}$. Slides were then washed with a stringent wash solution $(1: 10$ dilution of standard sodium citrate solution) at $50-55^{\circ} \mathrm{C}$ for $5 \mathrm{~min}$. All other procedures were as described for tissue sections. Positive controls were included in each staining run.

Table II. HER2 protein overexpression and HER2 gene amplication in tissue sections.

\begin{tabular}{|c|c|c|c|c|c|}
\hline & \multicolumn{5}{|c|}{ IHC } \\
\hline & 0 & $1+$ & $2+$ & $3+$ & Total \\
\hline \multicolumn{6}{|l|}{$\mathrm{CISH}$} \\
\hline Amplified & 2 & 1 & 6 & 16 & 25 \\
\hline Non-amplified & 18 & 7 & 3 & 5 & 33 \\
\hline Total & 20 & 8 & 9 & 21 & 58 \\
\hline Gene amplification rate $(\%)$ & 10.0 & 12.5 & 66.6 & 76.2 & 43.1 \\
\hline
\end{tabular}

IHC, immunohistochemistry. 
Table III. HER2 protein overexpression and HER2 gene amplification in FNAC specimens.

\begin{tabular}{|c|c|c|c|c|c|}
\hline & \multicolumn{5}{|c|}{ IHC } \\
\hline & 0 & $1+$ & $2+$ & $3+$ & Total \\
\hline \multicolumn{6}{|l|}{$\mathrm{CISH}$} \\
\hline Amplified & 0 & 1 & 10 & 14 & 25 \\
\hline Non-amplified & 21 & 3 & 7 & 2 & 33 \\
\hline Total & 21 & 4 & 17 & 16 & 58 \\
\hline Gene amplification rate $(\%)$ & 0 & 25.0 & 58.8 & 87.5 & 43.1 \\
\hline
\end{tabular}

Table IV. Comparison of FNAC specimens and tissue sections in IHC assay.

\begin{tabular}{ccccrr}
\hline & & \multicolumn{3}{c}{ Tissue sections } \\
\cline { 3 - 6 } & IHC & $0 / 1+$ & $2+$ & $3+$ & 0 \\
FNAC specimens & $0 / 1+$ & 25 & 0 & 8 & 25 \\
& $2+$ & 0 & 3 & 13 & 21 \\
& $3+$ & 28 & 9 & 58 \\
\hline
\end{tabular}

FNAC, fine needle aspiration cytology; IHC, immunohistochemistry.

Table V. HER2 gene amplification score in FNAC specimens and tissue sections.

FNAC specimens Tissue sections

\begin{tabular}{|c|c|c|c|c|c|c|c|}
\hline Score & No. of cases & Chr17 & No. of cases & Score & No. of cases & Chr17 & No. of cases \\
\hline A & 0 & & & A & 2 & & \\
\hline B & 17 & & & B & 15 & & \\
\hline $\mathrm{C}$ & 4 & & & $\mathrm{C}$ & 5 & & \\
\hline \multirow[t]{2}{*}{$\mathrm{D}$} & 12 & + & 4 & $\mathrm{D}$ & 11 & + & 3 \\
\hline & & - & 8 & & & - & 8 \\
\hline \multicolumn{2}{|c|}{ No amplification } & 25 & & & & 25 & \\
\hline
\end{tabular}

FNAC, fine needle aspiration cytology; Chr17, chromosome 17.

Table VI. Comparison between FNAC specimens and tissue sections in the detection of HER2 gene amplification.

\begin{tabular}{lcccc}
\hline & & \multicolumn{2}{c}{ Tissue sections } & \\
\cline { 3 - 4 } & & Positive $(\%)$ & Negative $(\%)$ & Total $(\%)$ \\
\hline FNAC specimens & Positive & $21(36.2)$ & $4(6.9)$ & $25(43.1)$ \\
Total & Negative & $4(6.9)$ & $29(50.0)$ & $33(56.9)$ \\
\hline
\end{tabular}

FNAC, fine needle aspiration cytology. 


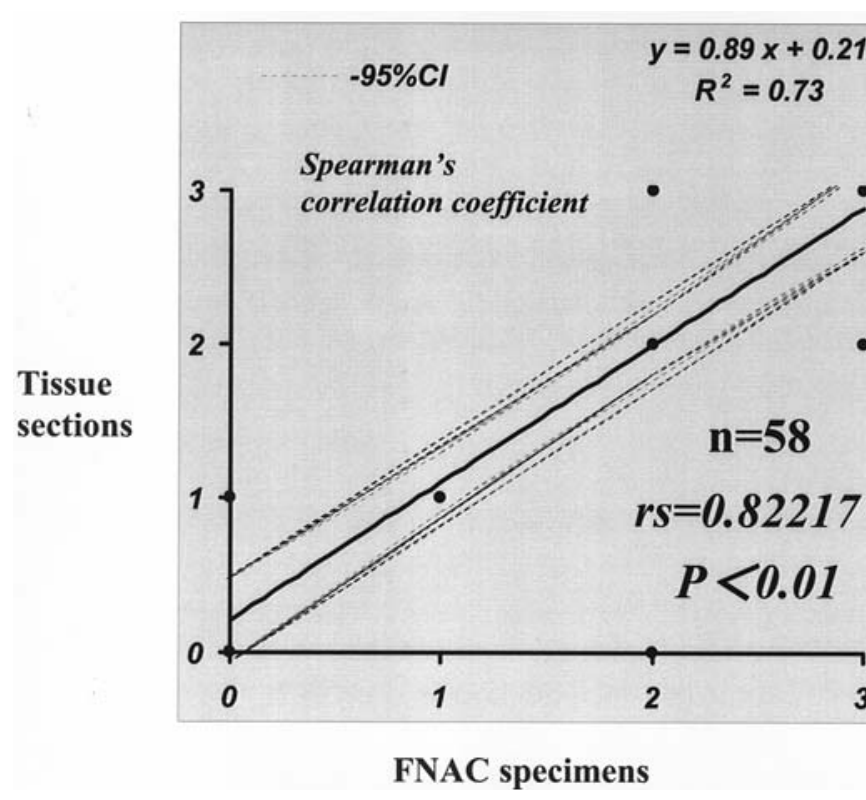

Figure 4. Correlation between HER2 protein expression on FNAC specimens and tissue sections. HER2 expression data from cytology specimens correlated significantly with those from tissue sections.

HER2 gene amplification. For both tissue sections and FNAC specimens, HER2 amplification was assessed according to the Zymed HER2 CISH Test Interpretation Guide, as shown in Fig. 2. Briefly, no amplification was defined as $\leq 5$ HER 2 signals per nucleus in at least $50 \%$ of cancer cells. Amplification was defined as $>10$ dots or signals or large clusters of HER2 per nucleus in at least $50 \%$ of the cancer cells. Scores were assigned as: A, clusters; B, multiple dots; and $\mathrm{C}$, clusters and multiple dots. Low amplification (score D) was defined as 5 to 10 dots (or signals) of HER2 per nucleus in at least $50 \%$ of cancer cells. In cases of low HER2 amplification, we used biotin-labeled Spot-light Chromosome 17 Centromeric Probe (Chr17 cen probe ) to confirm that the HER2 signals of the gene were due to HER2 gene amplification rather than polysomy of chromosome 17. When two signals were observed for Chr17 in a nucleus, we considered any extra HER2 dots to be caused by HER2 amplification (Fig. 3). We examined the correlations between the data from cytology specimens and tissue sections with a $2 \times 2$ table for sensitivity, specificity, and accuracy.

\section{Results}

HER2 expression. HER2 protein scores for tissue sections are shown in Table II. Twenty cases had a score of 0,8 cases had a score of $1+, 9$ cases had a score of $2+$, and 21 cases had a score of $3+$. HER2 protein scores for FNAC specimens are shown in Table III. Twenty-one cases had a score of 0,4 cases had a score of $1+, 17$ cases had a score of $2+$, and 16 cases had a score $3+$. Assuming that cases with a score of $1+$ or 0 are in the same category, as the difference between score 0 and score $1+$ is not clinically important, accuracy was $75.9 \%$ (44/58 cases) (Table IV). When histological type was considered, concordance between FNAC samples and tissue sections (assuming cases with a score of $1+$ or 0 are in the same category) was $75.0 \%$ (15/20 cases) for papillotubular carcinoma, $83.3 \%$ (5/6 cases) for solid tubular carcinoma, $77.4 \%$ (24/31 cases) for scirrhous carcinoma, and 0\% (0/1 case) for mucinous carcinoma. There was a significant correlation between the cytology specimens and tissue sections with respect to accuracy in the analysis of HER2 protein status [correlation coefficient, rs, was $0.89(\mathrm{P}<0.01$, $\mathrm{n}=58)$ ] (Fig. 4).

HER2 amplification. HER2 amplification data for tissue sections are shown in Table V. Twenty-five cases (43.1\%) showed gene amplification, and 33 cases showed no amplification. Among cases with amplification of $H E R 2,2$ cases had a score of A, 15 cases had a score of B, 5 cases had a score of $\mathrm{C}$, and 11 cases had a score of D. In 3 of the 11 cases with score D, low HER2 amplification was confirmed with the Chr17 cen probe. Among tissue sections, the percentage of cases with HER2 amplification relative to the protein score was $10.0 \%$ for score 0 (2/20 cases), $12.5 \%$ for score $1+(1 / 8$ cases $), 66.7 \%$ for score $2+(6 / 9$ cases $)$, and $76.2 \%$ for score $3+(16 / 21$ cases) (Table II). The HER2 scores on FNAC specimens are shown in Table V. Twentyfive cases $(43.1 \%)$ showed amplification of HER2, and 33 cases showed no amplification. Among cases with gene amplification, 0 cases had score A, 17 had score B, 4 had score $\mathrm{C}$, and 12 had score D. Of the 12 cases with score D, 4 were confirmed to have low HER2 amplification with the Chr17 cen probe. On FNAC specimens, the percentage of cases with amplification of $H E R 2$ relative to the protein score was $0 \%(0 / 21$ cases) for score $0,25.0 \%$ (1/4 cases) for score $1+, 58.8 \%$ (10/17 cases) for score $2+$, and $87.5 \%(14 / 16$ cases) for score $3+$ (Table III). With respect to histologic types, concordance was $85.0 \%$ (17/20 cases) in papillotubular carcinoma, $83.3 \%$ (5/6 cases) in solid tubular carcinoma, $87.1 \%$ (27/31 cases) in scirrhous carcinoma, and $100.0 \%(1 / 1$ case) in mucinous carcinoma. The sensitivity, specificity and accuracy for detection of HER2 gene amplification in cytology specimens in comparison to tissue sections were $84.0 \%$ (21/25 cases), $87.9 \%$ (29/33 cases), and $86.2 \%$ (50/58 cases), respectively (Table VI). Our results suggest that FNAC specimens can be used for detection of HER2 amplification and overexpression in invasive breast cancer.

\section{Discussion}

Trastuzumab and trastuzumab with chemotherapy are more effective treatment strategies for cancers with HER2 amplification than for those without amplification (1-4). For some studies, we found good concordance between CISH and FISH (15-20). The main difficulty in adopting FISH for clinical diagnostics is the need for fluorescence microscopy, which is not done in most routine diagnostic laboratories. Moreover, because fluorescence signals fade within a few weeks, hybridization results must be recorded with expensive digital cameras. To address these practical limitations, we used the CISH method because the probe can be detected with a simple IHC-like peroxidase reaction.

Although CISH-based analysis of HER2 gene amplification has been reported for tissue sections of breast cancer $(16,17,21)$, analysis of HER2 amplification in cytology specimens has 
not been reported. The aim of the present study was to determine whether FNAC specimens can be used to examine HER2 gene amplification, and we thus compared the data from tissue sections and FNAC specimens.

We used the Spot-Light CISH Detection kit for analysis of cytology specimens. However, we were unable to obtain adequate signals and had to modify the manufacturer's protocol. These changes included a second fixation in $10 \%$ neutral buffered formalin for $1 \mathrm{~min}$ followed by $4 \%$ paraformaldehyde for $15 \mathrm{~min}$, denaturation at $80^{\circ} \mathrm{C}$ for $3 \mathrm{~min}$, then $90^{\circ} \mathrm{C}$ for $3 \mathrm{~min}$, and a washing in a stringent solution sodium citrate at $72^{\circ} \mathrm{C}$ for 5 min followed by a washing in a 1:10 dilution of sodium citrate at $50-55^{\circ} \mathrm{C}$ for $5 \mathrm{~min}$. With this modified protocol, we were able to obtain adequate signals on the cytology specimens.

The HER2 gene amplification rate is high (43.2\%) on FNAC specimens and tissue sections, as the relatively large size of tumors in the present study would suggest that they were examined for hormone receptor expression. Accordance between results in FNAC and tissue specimens did not differ among histologic types. With respect to HER2 protein expression, all FNAC specimens with a score of 0 or $1+(25$ cases) had score of 0 or $1+$ on tissue sections. Most $(81.3 \%$, $13 / 16$ cases) FNAC specimens with protein scores of $3+$ also had a score of $3+$ on tissue sections, and the remaining 3 cases with a HER 2 protein score of $3+$ showed amplification of the HER2 gene on tissue sections. However, only $35.3 \%$ (6/17 cases) of FNAC specimens with a HER2 protein score of $2+$ had the same score on tissue sections. These findings suggest that for cases with HER2 protein scores of $0,1+$, or $3+$, FNAC specimens may be used instead of tissue sections without a loss of accuracy. However, the low accordance between FNAC specimens and tissue sections for cases with a score of $2+$ indicates that FNAC cannot be substituted for tissue sections under these conditions.

With respect to HER2 gene amplification, the sensitivity, specificity, and accuracy for the detection of HER2 gene amplification in FNAC specimens compared with that in tissue sections were $84.0 \%$ (21/25 cases), $87.9 \%$ (29/33 cases), and $86.2 \%$ (50/58 cases), respectively. Four of the 25 cases with HER 2 gene amplification on tissue sections were negative for amplification on FNAC specimens. We believe that these false-negative results may have been due to sampling errors. In other words, the cells were not aspirated from the cancer nest. Increasing the quality of FNAC specimen by aspirating from several areas of the cancer may improve the accuracy of detection by FNAC. There were 4 of 33 cases that were negative for the HER2 gene on tissue sections were positive for amplification on FNAC specimens. FNAC specimens from these 4 false-positive cases had an amplification score of D, and FNAC specimens had to be examined with a Chr17 cen probe. Of these 4 cases, 2 had a score of $\mathrm{D}$ on both FNAC specimens and tissue sections.

Because FNAC is a minimally invasive technique for obtaining tissue samples, we are able to easily obtain multiple specimens. With a combination of tests for some FNAC specimens, we can correctly assess HER2 status during the pretreatment stage. Moreover, if the core needle biopsy specimen is small or if cancer cells are crushed, it is beneficial to assess the HER2 status with FNAC specimens.

\section{References}

1. Pegram M, Hsu S, Lewis G, et al: Inhibitory effects of combinations of HER-2/neu antibody and chemotherapeutic agents used for treatment of human breast cancers. Oncogene 18: 2241-2251, 1999.

2. Vogel CL, Cobleigh MA, Tripathy D, et al: Efficacy and safety of trastuzumab as a single agent in first-line treatment of HER2overexpressing metastatic breast cancer. J Clin Oncol 20: 719$726,2002$.

3. Tsuda H, Akiyama F, Terasaki H, et al: Detection of HER2/neu (c-erbB-2) DNA amplification in primary breast carcinoma. Interobserver reproducibility and correlation with immunohistochemical HER-2 overexpression. Cancer 92: 2965-2974, 2001.

4. Slamon DJ, Leyland-Jones B, Shak S, et al: Use of chemotherapy plus a monoclonal antibody against HER2 for metastatic breast cancer that overexpresses HER2. N Engl J Med 344: 783-792, 2001.

5. Ross JS and Fletcher JA: HER-2/neu (c-erb-B2) gene and protein in breast cancer. Am J Clin Pathol 112: S53-S67, 1999.

6. Shak S: Overview of the trastuzumab (Herceptin) anti-HER2 monoclonal antibody clinical program in HER2 overexpressing metastatic breast cancer. Herceptin multinational investigator study group. Cancer Res 6: 71-77, 1999

7. Cobleigh MA, Vogel CL, Tripathy D, et al: Multinational study of the efficacy and safety humanized anti-HER2 overexpression in metastatic breast cancer that has progressed after chemotherapy for metastatic disease. J Clin Oncol 17: 2639-2648, 1999.

8. Slamon DJ, Clark GM, Wong SG, et al: Human breast cancer: correlation of relapse and survival with amplification of the HER-2/neu oncogene. Science 235: 177-182, 1987.

9. Slamon DJ, Godolphin W, Jones LA, et al: Studies of the HER-2/ neu proto-oncogene in breast and ovarian cancer. Science 244 : 707-712, 1989.

10. Corkill ME and Katz R: Immunocytochemical staining of c-erbB-2 oncogene in fine-needle aspirates of breast carcinoma: a comparison with tissue sections and other breast cancer prognostic factors. Diagn Cytopathol 11: 250-254, 1994.

11. Troncone G, Panico L, Vetrani A, et al: C-erbB-2 expression in FNAB smears and matched surgical specimens of breast cancer. Diagn Cytopathol 14: 135-139, 1996.

12. Troncone G, Zeppa P, Fulciniti F, et al: C-erbB-2 expression and DNA ploidy status in breast cancer cells obtained by fine needle aspiration (FNA). Cytopathol 4: 195-205, 1993.

13. Tiniakos DG, Robinson KB, Greenwood H, et al: c-erbB-2 and P53 expression in breast cancer fine needle aspirates. Cytopathology 7: 178-186, 1996.

14. Solomides CC, Zimmerman R and Bibbo M: Semiquantitative assessment of c-erbB-2 (HER2) status in cytology specimens and tissue sections from breast carcinoma. Anal Quant Cytol Histol 21: 121-125, 1999.

15. Arnould L, Denoux Y, MacGrogan G, et al: Agreement between chromogenic in situ hybridization (CISH) and FISH in the determination of HER2 status in breast cancer. Br J Cancer 88: 1587-1591, 2003.

16. Dandachi N, Dietze O and Hauser-Kronberger C: Chromogenic in situ hybridization: a novel approach to a practical and sensitive method for the detection of HER2 oncogene in archival human breast carcinoma. Lab Invest 82: 1007-1014, 2002.

17. Tanner M, Gancberg D, Di Leo A, et al: Chromogenic in situ hybridization: a pratical alternative for fluorescence in situ hybridization to detect HER-2/nеu oncogene amplification in archival breast cancer samples. Am J Pathol 157: 1467-1472, 2000.

18. Diaz LK, Gupta R, Kidwai N, et al: The use of TMA for interlaboratory validation of FISH testing for detection of HER2 gene amplification in breast cancer. J Histochem Cytochem 52: 501-507, 2004.

19. Gupta D, Middleton LP, Whitaker MJ, et al: Comparison of fluorescence and chromogenic in situ hybridization for detection of HER2/neu oncogene in breast cancer. Am J Clin Pathol 119: 381-387, 2003.

20. Zhao J, Wu R, Au A, et al: Determination of HER2 gene amplification by chromogenic in situ hybridization (CISH) in archival breast carcinoma. Mod Pathol 15: 657-665, 2002.

21. Kumamoto H, Sasano H, Taniguchi T, et al: Chromogenic in situ hybridization analysis of HER2/neu status in breast carcinoma: application in screening of patients for trastuzumab (Herceptin) therapy. Pathol Int 51: 579-584, 2001. 